\title{
Artesanos y artesanías de los pueblos precordilleranos de la zona circundante al Salar de Atacama (II región, Chile)
}

HAROLd KRUSELL ${ }^{1}$

\section{Introducción}

Así como la humanidad ha desarrollado un poder avasallador frente a otras especies del planeta, algunas de las cuales se han extinguido y otras están muy prontas a desaparecer, también ha cobrado conciencia de que el alcance de sus conocimientos es muy escaso para correr el riesgo de perder una sola forma de vida.

Esta posición válida con respecto a organismos inferiores lo es también, y con mayor razón, para formas de vida superior, incluyendo al ser humano en el sentido de su supervivencia fisiológica, cultural y su equilibrio armónico con el medio en que le tocó desarrollarse.

De allí la necesidad, para el hombre del futuro, de preservar valores étnicos y culturales que tal vez no tengan vigencia en el marco actual de vida y por ello tiendan a desaparecer.

La tarea universitaria en este caso es rescatar todos aquellos valores y, lejos de hacer un museo viviente, darle actualidad fundamentalmente en su aspecto económico (entendiendo la economía como ecología humana).

\section{Ambiente}

En el norte de Chile, al interior de Antofagasta cortado por el Trópico de Capricornio, se encuentra el gran Salar de Atacama. Ubicado en una hoya hidrográfica cerrada al occidente por la Cordillera Domeyko y el oriente por la cadena andina en cuyos faldeos se encuentran profundas quebradas por donde corren insignificantes riachuelos que hacen florecer la vida en pleno desierto y que luego desaparecen bajo la arena para alimentar el Salar.

1 Departamento de Artes Visuales, Universidad del Norte, Antofagasta, CHILE.
En medio de este vasto escenario y contrariando la horizontalidad del paisaje se yerguen los oasis con sus característicos algarrobos y chañares entre algunas otras especies frutales, única fuente maderera y a la vez importante alimento para el ganado que se suma a la mezquina agricultura (maíz, trigo, alfalfa y hortalizas), la vegetación herbácea de algunas vegas solitarias (grama, carrizo y junquillo) y a los pastos de los faldeos cordilleranos que crecen en las épocas de lluvias (malvilla, iloca) en las llamadas estancias que sustentan el ganado entre septiembre y abril.

Completa la flora típica atacameña el cactus candelabro que crece de preferencia hacia las alturas que le permiten alcanzar la humedad de las nubes bajas y algunas variedades de arbustos de $50 \mathrm{~cm}$ de altura que se extienden raleados en vastas planicies, entre ellos, el rica-rica, el copa-copa, el cachiyuyo y otras yerbas como la brea, el bailahuén, que complementan la alimentación de burros, mulas y ganado.

En base a esta escasa vegetación se mantiene un reducido número de cabezas de ganado, siendo el más importante numéricamente en esta zona el ganado lanar, especialmente donde abundan las vegas y los sembrados de alfalfa.

El más importante, tanto históricamente como por su rusticidad, valor de su fibra, de su carne y su resistencia para atravesar el desierto es la llama. Aunque desplazada como medio de transporte por el burro, la mula y el camión, sigue siendo el mejor acondicionado para los rigores del clima. Este animal significó para el atacameño lo que el caballo para el conquistador.

Casi extinguidas se encuentran las vicuñas, vizcachas y chinchillas. Menos perseguidos por el hombre, pero a prudente distancia de los oasis, zorros, gatos monteses, flamencos rosados, avestruces y ratones. 


\section{El hombre}

En medio de la dureza del ambiente que dificulta el arraigo de la vida, aparece el hombre desde sus estadios más primitivos hasta el actual. Desde el cazador al pastor, al agricultor y al minero industrial (mineral de hierro El Laco y el Litio del Salar, dentro de poco).

Este desarrollo continuado indica que pese al limitado número de habitantes condicionado por el parámetro que significa el flujo de agua en los oasis, se ha ido forjando el carácter del pueblo atacameño que como el chañar de tronco delgado y nudoso, de difícil elaboración, se destaca por su resistencia y dureza como el más apto a la vida en el desierto.

El aislamiento, condición determinante de la vida en el oasis, acentuado por la monotonía del clima, el estatismo del paisaje y la oscilación de los hábitos del hombre, entre una vida sedentaria confinada a un punto verde en el desierto, y a una vida de pastor y arriero que cubre grandes distancias por períodos largos de tiempo, dan la tónica a su personalidad, de costumbres fuertemente arraigadas en un alto porcentaje de sangre nativa.

Las influencias que han ido dando fisonomía al desarrollo cultural de este pueblo han chocado contra el ambiente y el ancestro, constituyendo lo que el arqueólogo llama los "horizontes culturales", que se caracterizan por objetos típicos de una cultura, intrusivos o no, pero que no han perdurado en el tiempo, excepto en algunas manifestaciones.

Así la civilización occidental llegó a esta zona principalmente a través de los misioneros españoles. Por ser el cristianismo superior, más complejo y acompañarse de la espada, se impuso en un comienzo. Pero el ancestro aborigen, la fuerza del ambiente y el natural espíritu religioso del indio que no asimila necesariamente sus conceptos abstractos, con el transcurso del tiempo dan sello propio a la nueva religión.

\section{Situación actual}

Hoy, que el esfuerzo del país se dirige prioritariamente al desarrollo industrial y tecnológico, se tiende a olvidar esta realidad humana y cultural.

Al carecer la zona en tiempo pasado de grandes riquezas que explotar, no atrajo el interés del inmigrante extranjero o del colono chileno, cuyo foco de atracción ha sido la minería (exceptuando la caza de la chinchilla).

Por el contrario, estos centros industriales mineros produjeron un drenaje en la población joven de estas comunidades, que se transformó en tradición, no tanto por las perspectivas de empleo con buenos sueldos, sino por las escasas o nulas perspectivas que se le presentan en sus propias localidades.

Los niños cursan sólo sus primeros años básicos en las escuelas de su pueblo. San Pedro de Atacama tiene hasta $8^{\circ}$ Año Básico y un internado al que llegan de todos los pueblos del Salar.

El joven que desea seguir enseñanza media debe ir a Calama (105 km de San Pedro y $200 \mathrm{~km}$ de Peine o Socaire) con un tráfico de vehículos muy irregular.

Estudiante que sale, difícilmente vuelve. El joven que no se ha ido por estudios, se va por su servicio militar a los 18 años.

La confrontación de los dos sistemas de vida ha provocado un desarraigo de las costumbres, sin un aporte tecnológico que las supla. Así dejaron de elaborar el tiesto de greda e hizo su aparición la olla de aluminio. Pero es una olla que no fabrican sino que la adquieren. En esta relación con el mundo circundante tuvieron y tienen relación desventajosa por cuanto el intercambio de productos es principalmente en un solo sentido (excepto la artesanía). Ellos reciben objetos a cambio de su capital humano. El hombre joven. El mejor.

En este sistema sólo quedan dos alternativas: el aislamiento total y autoabastecimiento (impracticable) o la desintegración total y la desaparición a corto plazo de estas comunidades, con la muerte de los habitantes más antiguos que se llevan consigo los restos de sus tradiciones, y la asimilación de sus elementos jóvenes por la "civilización”. Esto último es para estas comunidades como si murieran, situación que produce un efecto depresivo con respecto al futuro en sus propios habitantes. Quedan en ellas los ancianos y los niños, los que consumen menos proteínas. El hombre en edad de trabajo -que las produce y las consume en mayor cantidad- migra.

Si bien el aumento vegetativo de la población nunca fue mayor, por la limitación del agua y terreno 
cultivable, la explotación agrícola ha sido mejor, combinándose en otras épocas por la función de contacto entre el sur de Bolivia y el noroeste de Argentina con la pampa.

La adaptación del hombre joven a la vida urbana es en general penosa, por cuanto pasa a formar parte de sus más bajos estratos sociales o del grupo marginado de los inadaptados sociales (alcohólicos).

\section{Valor de la artesanía}

Las posibles soluciones económicas a esta situación, aún a largo plazo, tal vez se produzcan con la reforestación de tamarugos en una vasta superficie adyacente al Salar o con la construcción de la carretera internacional que una a Salta con Antofagasta por el paso de Huaytiquina o con la explotación del mineral de hierro del Laco y del Litio del Salar.

La artesanía posee en la actualidad doble valor, por un lado representa un ingreso que permite al hombre complementar su economía y depender de sus propias manos sin esperar la gran solución (la panacea tecnológica del futuro), que tal vez no llegue nunca para él, y a la vez expresar su propio mundo, redescubriendo su vocación artesanal, presente a lo largo de todo su pasado en diversas manifestaciones que van desde la cerámica, cestería, tejidos hasta los tallados en madera y piedra y trabajos en metal.

Si bien la tradición se interrumpió en muchos de estos rubros, se mantuvo en los tejidos, y su sentido está latente en el alma del mestizo.

Casi en su totalidad estos pueblos -unos más, otros menos- subsisten con una economía degradada, en la que cada hombre debe realizar varias tareas distintas para poder reunir lo indispensable para vivir. Todos son agricultores, todos son artesanos. Es el caso en que la artesanía es fundamental. La agricultura y ganadería proporcionan los alimentos (o parte de ellos) y las artesanías un ingreso de dinero que les permite adquirir productos urbanos. Internamente se practica el trueque con bastante frecuencia.

\section{Valor de cambio del trabajo artesanal}

El valor que el hombre de la precordillera atribuye a sus bienes corresponde a su función vital y no estrictamente a su valor de cambio.

El trueque se realiza porque algo se necesita y porque algo se tiene más allá de las necesidades propias.
No con un sentido comercial. Se fija un precio a un producto para financiar con ello un trabajo (por ejemplo, un canal de regadío) o en función de lo que necesita comprar al camión de la ECA en su próximo recorrido. Este tipo de intercambio se da entre las quebradas principalmente.

La artesanía, en cambio, es el medio de contacto entre el hombre urbano y el lugareño. Antes, la gente se recluía en sus casas y los niños se escondían al ver llegar un turista. Hoy se le sale a recibir y se le ofrece la artesanía. En este "diálogo", la artesanía es el medio de expresión y el turista potencial receptor de su mensaje.

El hombre ha tomado conciencia de su ingenuidad frente al afuerino y la ha superado con creces. No hay competencia de precios entre artesanos.

Si se compara el valor de una frazada de lana de buena calidad en una casa comercial de Antofagasta o Calama, con una frazada de lana de Socaire o Talabre, se ve que el valor atribuido al objeto no corresponde a una relación de precios con otros similares de los centros comerciales de la provincia. Tampoco puede considerarse un precio mermado o atrasado. Curiosamente, el valor de la lana en la región se mantiene al día con su precio internacional. Pero en períodos difíciles el artesano mendiga la venta de sus productos. Pierde conciencia de su valor de cambio y prima sólo su necesidad inmediata.

Aquí aparece el intermediario, que aprovechándose del aislamiento de estas localidades saca excesivas ganancias de su función y a la vez impone su criterio en lo que él considera "mejor" para su negocio, dirigido a un público vasto y poco conocedor, al cual interesa más, tal vez, salir de un compromiso con algún pariente o amigo que visita en su viaje, llevándole algo "típico", que el objeto mismo que compra, o la buena factura por sobre su valor expresivo en el mejor de los casos. ${ }^{2}$

2 En 1974 el Plan Cordillera Caritas Chile programó un curso de Alfombrería en el valle de Lluta, al cual concurrieron 16 personas de la región del Salar (11 personas de Socaire, 2 personas de Camar y 3 personas de Talabre). Fueron designados por las correspondientes Juntas de Vecinos, excepto en Camar, que fueron sólo los que quisieron ir. El objetivo es formar en Socaire un taller vecinal de Alfombrería. El curso estuvo a cargo del profesor Armando Falloni, de nacionalidad peruana, y promovido en la zona por Eduvigis Hidalgo Cortez, de Caritas Chile. 
En lo que el artesano manifiesta un claro sentido comercial es en el destino de su producto. Elabora objetos para su uso y otros para la venta, y no hay confusión entre ambos.

Considera de mala suerte vender sus herramientas; según la creencia, vuelve al hombre flojo e inútil. Elabora sus herramientas lo mejor que puede, no importando el tiempo invertido en ello. Venderlas es vender la prolongación de sus manos.

\section{Plan cordillera}

En 1963-1966 la Universidad del Norte participó en un convenio con Caritas Chile. Se eligió a Toconao como pueblo piloto y se ofreció cambiar en términos de trueque, alimentos por figuras talladas en piedra volcánica y trabajos comunitarios, entre ellos el camino a la segunda cantera.

Hoy la artesanía presenta dos líneas claramente distintas. La primera la constituyen las artesanías funcionales, para el autoabastecimiento y que por lo general no se vende, y la segunda es de los productos vendibles, ya sean funcionales o decorativos, manifestándole una continua búsqueda de nuevas formas y, a la vez, la estandarización de los tipos de mayor venta, lo que se aprecia tanto en las técnicas tradicionales como en las inducidas (tallado en piedra).

Este fenómeno se debe a la suplantación de los valores autóctonos por los valores urbanos; situación reinante en todos los aspectos de la vida en estas comunidades.

Antiguamente el objeto artesanal respondía a una necesidad, ya sea funcional, decorativa o de culto; hoy interesa principalmente por su valor económico.

Para los "puristas" conviene recordar que es condición del arte el ser reflejo de una realidad (Cuadro 1).

\section{Método de trabajo}

Desde el año 1968 se han hecho viajes periódicos a la zona, manteniendo contacto directo con los artesanos y sus organizaciones (Cooperativa y Juntas de Vecinos).

En 1971 se levantó un Catastro de Artesanos y se entregó junto a un informe a SERCOTEC, con el objeto de programar la ayuda a este sector, que se materializó en abastecimiento de materia prima y cauces de comercialización de la artesanía.
En mayo 1974 se realizó un muestreo de la producción artesanal de toda la zona en ese momento, material que se encuentra en el Museo Regional de la Universidad del Norte -Antofagasta-, junto a muestras de la producción artesanal de los comienzos del Plan Cordillera (las piezas de mayor interés en este aspecto se encuentran en el Museo de San Pedro de Atacama y colecciones particulares).

Se hizo en esta oportunidad un nuevo informe para SERCOTEC.

El Catastro de Artesanos se ha venido reactualizando hasta el mes de enero de 1975.

\section{Catastro de artesanos de los pueblos precordilleranos de la zona circundante al Salar de Atacama}

San Pedro de Atacama - Toconao - Talabre - Camar Socaire - Peine.

Con el propósito de valorar críticamente los resultados del Plan Cordillera, el Departamento de Artes Visuales de la Universidad del Norte realizó el año 1971 un Catastro de Artesanos existentes en el mencionado sector. De allí en adelante este catastro se ha venido reactualizando, correspondiendo su última revisión al mes de mayo de 1974.

\section{San Pedro de Atacama}

Ubicación geográfica: $22^{\circ} 55^{\prime}$ Lat. S; $68^{\circ} 12^{\prime}$ Long. O.

Altura: 2436 m.snm

Pueblo de aproximadamente 1130 habitantes, agrupados en 18 ayllos, centro turístico, y la mayor producción agrícola y ganadera de la zona del Salar de Atacama. No se producen allí artesanías, salvo algunas excepciones. La producción ganadera, podría abastecer de lana de oveja a los artesanos de Toconao y Peine.

La mayor cantidad de tierra apta para cultivo en el delta del San Pedro y la posibilidad de mejor aprovechamiento del flujo de agua proveniente de los ríos San Pedro y Vilama (el oasis con más agua de la zona del Salar) hacen centrar el esfuerzo y la esperanza de la población en el trabajo agrícola. Se suman a esto las experiencias hechas por CORFO y SAG con el tamarugo y ganado. 
ARTESANOS Y ARTESANIAS DE LOS PUEBLOS PRECORDILLERANOS...

\begin{tabular}{|c|c|}
\hline Funcionales & Comerciales \\
\hline $\begin{array}{l}\text { Tejidos } \\
\text { Frazadas } \\
\text { Mantas } \\
\text { Gorros } \\
\text { Calcetas } \\
\text { Casimires para ropa } \\
\text { Lazos lana (para burro y animales menores) } \\
\text { Bolsos } \\
\text { Guantes }\end{array}$ & $\begin{array}{cl}\text { Tejidos } & \\
& \text { Frazadas } \\
& \text { Calcetas } \\
& \text { Guantes } \\
& \text { Pisos } \\
& \text { Lazos lana } \\
& \text { Fajas } \\
& \text { Gorros }\end{array}$ \\
\hline $\begin{array}{l}\text { Cueros } \\
\text { Lazos } \\
\text { Riendas } \\
\text { Correas para mulo y caballo } \\
\text { Pencas }\end{array}$ & $\begin{array}{l}\text { Cueros } \\
\text { Coquitos } \\
\text { Llamitos } \\
\text { Bombos }\end{array}$ \\
\hline $\begin{array}{l}\text { Instrumentos musicales } \\
\text { (Se traen desde Bolivia) }\end{array}$ & $\begin{array}{c}\text { Instrumentos musicales } \\
\text { Clarines } \\
\text { Quenas } \\
\text { Bombos } \\
\text { Tambores } \\
\text { Zampoñas }\end{array}$ \\
\hline $\begin{array}{l}\text { Instrumentos madera (utensilios) } \\
\text { Telar de campo } \\
\text { Telar de suelo } \\
\text { Palillos } \\
\text { Ruecas } \\
\text { Husos }\end{array}$ & $\begin{array}{l}\text { Instrumentos madera (Utensilios) } \\
\text { Cucharas (frutales) } \\
\text { Mazos } \\
\text { Bandejas (cactus) } \\
\text { Lámparas (cactus) }\end{array}$ \\
\hline $\begin{array}{l}\text { Tallados piedra volcánica } \\
\text { Bloque construcción (liparita) }\end{array}$ & $\begin{array}{l}\text { Tallados piedra volcánica } \\
\text { Bloque construcción (liparita) } \\
\text { Figuras con telares } \\
\text { Burros } \\
\text { Torres } \\
\text { LIamos } \\
\text { Virgen de Licancaur (liparita) } \\
\text { Fenómenos } \\
\text { Ceniceros } \\
\text { Figuras de animales (liparita) } \\
\text { Otras }\end{array}$ \\
\hline Lapidaria & $\begin{array}{r}\text { Lapidaria }(\text { Onix }) \\
\text { Ceniceros } \\
\text { Corazones } \\
\text { Cruces }\end{array}$ \\
\hline $\begin{array}{l}\text { Piedra y madera } \\
\text { Molinos }\end{array}$ & \\
\hline
\end{tabular}

Cuadro 1. Artesanías que se producen en la zona circundante al Salar de Atacama. 
El fenómeno de emigración de la población joven hacia centros industriales, la inmigración de población proveniente de poblados cercanos, que van tomando el lugar de los que se van, el mayor grado de mestizaje y la presencia de funcionarios públicos, parecen haber inhibido la vocación artesanal de la población.

La existencia de arcillas excelentes, en cerámica arqueológica del museo como fuente de inspiración, y el turismo, hacen factible el desarrollo de una artesanía cuyo mercado está a la espera del producto.

Las fiestas tradicionales que se celebran para el día del patrono de la localidad se caracterizan por la procesión y bailes con enmascarados (catimbanos, achaches, San Pedro, San Pablo, El Toro). Fiestas similares son comunes en varios poblados. Por esta razón, es conveniente desarrollar, entre los niños, las técnicas de confección de máscaras en papel cortado y cuero.

La Escuela Agrícola de San Pedro es el lugar indicado, ya que a ella concurren niños de todas las comunidades vecinas, siendo los más entusiastas cultores de esta tradición. Este trabajo ha sido iniciado por el Departamento de Artes Visuales en la Escuela de San Pedro de Atacama. Las festividades de los patronos de cada pueblo son motivo de atracción turística.

\section{Artesanos de San Pedro de Atacama:}

Emilia Soza, tejidos.

Sra. Coca, maderas de cactus.

Sra. Aimán, tejidos.

Necesidades: Un taller vecinal, que sirva a los artesanos, centros de madres y niños, incentivando la artesanía cerámica y las máscaras.

\section{Toconao}

Ubicación geográfica: $23^{\circ} 11^{\prime}$ Lat. S; $68^{\circ} 01^{\prime}$ Long. O.

\section{Altura: 2485 m.snm}

Pueblo situado en un oasis a $38 \mathrm{~km}$ al sur de San Pedro de Atacama, de 600 habitantes aproximadamente (170 familias). Su actividad económica está centrada en dos rubros: producción agropecuaria (frutales) y producción artesanal.
La producción de frutales (pera, membrillo, breva) constituía hasta el inicio del "Plan Cordillera" la principal y única fuente de ingreso de la población, existiendo la artesanía textil a un nivel de autoabastecimiento. Las artesanías en piedra no se producían.

El Plan Cordillera fijó a Toconao como pueblo piloto y desde 1966 adelante empieza a aparecer una gama bastante variada de artesanías, dedicándose a ello gran parte de la población y llegando a constituir en poco tiempo la principal fuente de ingreso, quedando en segundo lugar los frutales.

Se formó la Cooperativa Campesina de Toconao, que ha centralizado la venta de sus artesanías y también de Camar, Talabre y Socaire. Cuenta con 90 cooperados. La mayor parte de los artesanos de Toconao no son cooperados y venden indistintamente a la Cooperativa o directamente al turista, según sea la conveniencia. En esta temporada, diciembre 73, enero, febrero, marzo 74, se redujo considerablemente el flujo turístico, disminuyendo las ventas y bajando en consecuencia la producción, quedando el ingreso por este rubro por debajo del de los frutales. Para la temporada otoño-invierno 74 , se producirá un repunte en el rubro artesanía debido a dos importantes pedidos desde la capital, hechos por intermedio de la Cooperativa. Estos pedidos son de CEMA y de la Confederación de Cooperativas Campesinas y coinciden con el término de las faenas agrícolas pudiendo los artesanos centrarse en su trabajo.

La producción artesanal textil es abundante y variada, pese a no tener suficiente ganado, abasteciéndose de materia prima en San Pedro, Socaire y Talabre.

Se teje a palillo, telar de campo y de suelo.

En cambio, para los tallados en piedra, cuentan con abundante material. Existen dos canteras de Liparita (piedra blanca de Toconao) y la piedra volcánica gris se encuentra a poca distancia del pueblo. En esta última se trabajan las figuras de torres, burros, viejas, llamos y fenómenos, manifestándose un cierto grado de especialización de algunos artesanos en algunas líneas del tallado. Tallan esta piedra, hombres, mujeres y niños.

La piedra blanca es trabajada sólo por cuatro canteros y se produce en ella fundamentalmente el bloque de construcción y algunas figuras por encargos. La cantera es extraordinariamente sana, con fisuras 
verticales, rectas y espaciadas, dejando entre sí grandes bloques totalmente sanos de unos $3 \mathrm{~m}$ de ancho por $10 \mathrm{~m}$ de altura. No se extraen bloques grandes por falta de pedidos y por carecer de técnica adecuada. Se horada con barreno y se hacen cargas con pólvora, sistema que tritura la masa de la piedra. Las cuñas no dan buen resultado por lo poroso de la piedra que cede y amortigua el golpe o presión donde se le aplique.

Se han hecho ensayos en el laboratorio de Resistencia de Materiales del Departamento Construcción Civil de la Universidad del Norte para determinar las características de esta piedra, con el objeto de producir con ella soleras, dando resultados satisfactorios, pero el proyecto ha quedado en el papel.

La artesanía de la piedra de Toconao debe virar hacia una línea utilitaria, de aplicación en la arquitectura. Esto permitiría industrializar la cantera utilizando maquinaria que abarate los costos y que absorba la mano de obra de hombres adultos. ${ }^{3}$

\section{Artesanos de Toconao: Ver Cuadro 2.}

\section{Talabre}

Ubicación geográfica: $23^{\circ} 23^{\prime}$ Lat. S; $67^{\circ} 50^{\prime}$ Long. O.

\section{Altura: 3700 m.snm}

Pueblo ubicado a $32 \mathrm{~km}$ de Toconao, al fondo de una profunda quebrada muy cerca de la ruta a Huaytiquina. Viven allí 16 familias que suman en total 125 habitantes.

La principal actividad es la ganadería (aproximadamente 500 ovejas y 600 llamos). Tiene la mayor majada de llamos en la zona del Salar, lo cual es de gran importancia para la artesanía textil. Entre 1971 y 1974 ha experimentado una disminución de aproximadamente 100 cabezas de ovinos y un aumento de 200 auquénidos.

Posee una Escuela con un solo profesor que la atiende.

3 En enero de 1975 la directiva de la Cooperativa hacía trámites en SERCOTEC para la obtención de un préstamo para la adquisición de maquinaria, con el fin de cumplir con pedidos importantes de bloque de construcción desde Chuquicamata y Calama.
La población está esparcida a lo largo de 4 km, en tres caseríos en el fondo de la quebrada.

El aislamiento sería casi total si no fuera por el tráfico de camiones frigoríficos desde Argentina.

Producen buenos y variados tejidos, cuyas formas principales son: frazadas, mantas, fajas, llamitos, calcetas, gorros, pisos, etc., cuya venta les proporciona un ingreso, con pago no siempre inmediato.

$\begin{array}{ll}\begin{array}{l}\text { Artesanos de Talabre: } \\ \text { Sebastián Tejerina }\end{array} & \\ \text { Juan Río Flores } & \text { Carmela Soza } \\ \text { María Gutiérrez } & \text { Justina Gutiérrez } \\ \text { Víctor Gutiérrez } & \text { Lidia Soza } \\ \text { Angela Mamani } & \text { Aparicio Soza } \\ \text { Julia Mamani } & \text { Leandra Soza } \\ \text { Gaudiencia Soza } & \text { Daniel Armella } \\ \text { Eusebia Casimiro } & \text { Carmela Mamani } \\ \text { Eulogia Pachao } & \text { Uldina Armella } \\ \text { Juan Soza* } & \text { Emiliano Rores } \\ \text { Favio Soza Flores } & \text { Segundina Mamani } \\ \text { (fabricante de telares) } & \text { Cecilio González }\end{array}$

En total, 22 artesanos que están entregando productos, cuya venta se hace por intermedio de la Cooperativa de Toconao y directamente a negocios del ramo en Santiago.

\section{Camar}

Altura: 2600 m.snm

Caserío a $30 \mathrm{~km}$ al sur de Toconao, muy pobre, en el cual viven sólo cinco familias. La escasa agricultura y ganado ovino que poseen les son insuficientes para vivir, alcanzándoles sólo para subsistir.

Todas las mujeres y algunos hombres tejen, además tallan la piedra volcánica y hacen instrumentos musicales (tambores y clarines).

Los jefes de las cinco familias son:

1. Santos Regino Cruz

2. Alberto Tejerina

3. Norberto Tejerina

4. Gregorio Cruz

5. Pascual Soza.

4 Realizaron el curso de alfombras que se dictó en Arica en 1974. 
HAROLD KRUSSELL

\begin{tabular}{|c|c|c|c|c|c|c|c|}
\hline Nombre & $\begin{array}{l}\text { Piedra } \\
\text { volcánica } \\
\text { gris }\end{array}$ & $\begin{array}{c}\text { Piedra blanca } \\
\text { (liparita) } \\
\text { Cantero }\end{array}$ & $\begin{array}{l}\text { Tejidos en } \\
\text { telar de } \\
\text { campo }\end{array}$ & $\begin{array}{l}\text { Tejido en } \\
\text { telar (en el } \\
\text { suelo) }\end{array}$ & $\begin{array}{c}\text { Instrumentos } \\
\text { musicales }\end{array}$ & Cooperados & $\begin{array}{c}\mathbf{N}^{\circ} \\
\text { Cooperados }\end{array}$ \\
\hline Justo Mondaca & $\mathrm{X}$ & & & & & & $\mathrm{X}$ \\
\hline Luis Mondaca & $\mathrm{X}$ & & & & & & $\mathrm{X}$ \\
\hline Celestino Cruz & $X$ & $X$ & $\mathrm{X}$ & $\mathrm{X}$ & \multicolumn{3}{|c|}{ Administrador de la Cooperativa } \\
\hline María Tejerina & $X$ & & $\mathrm{X}$ & $\mathrm{X}$ & & $X$ & \\
\hline Francisco Tejerina & & $\mathrm{X}$ & $\mathrm{X}$ & \multicolumn{3}{|c|}{ Vicepdte. Consejo Adm. Cooperativa } & \\
\hline $\begin{array}{l}\text { Bartolina Mamani de } \\
\text { Tejerina }\end{array}$ & & & & \multicolumn{3}{|c|}{ Clarines } & \\
\hline Eleuteria Tejerina & & & $\mathrm{X}$ & & & & $\mathrm{X}$ \\
\hline Eliana Tejerina & & & $\mathrm{X}$ & & & & $\mathrm{X}$ \\
\hline Tito Tejerina $\mathrm{P}$. & $X$ & $X$ & & & & & $X$ \\
\hline Arsenia Silvestre & $\mathrm{X}$ & & $\mathrm{X}$ & $\mathrm{X}$ & $\mathrm{X}$ & $\mathrm{X}$ & \\
\hline Carlos Reyes & $\mathrm{X}$ & & & & Clarines & & $\mathrm{X}$ \\
\hline Justina Reyes & & & $\mathrm{X}$ & & & & $\mathrm{X}$ \\
\hline David Reyes & $\mathrm{X}$ & & & & & $\mathrm{X}$ & \\
\hline $\begin{array}{l}\text { Alejandro González y } \\
\text { señora }\end{array}$ & $\mathrm{X}$ & & & & & $\mathrm{X}$ & \\
\hline Jacobino Mamani & $\mathrm{X}$ & & & & & $\mathrm{X}$ & \\
\hline Rogelio Araya & & & & & $\mathrm{X}$ & $\mathrm{X}$ & \\
\hline Bonifacio Puca y señora & & & $\mathrm{X}$ & & (Quena) & & $\mathrm{X}$ \\
\hline Eugenio Cruz & $X$ & & & \multicolumn{2}{|c|}{ Secret. Cons. Cooperativa } & $\mathrm{X}$ & \\
\hline Marcos Gabia & $\mathrm{X}$ & $\mathrm{X}$ & & \multicolumn{2}{|c|}{ Pdte. Cons. Cooperativa } & $\mathrm{X}$ & \\
\hline Adrián González & $\mathrm{X}$ & & $\mathrm{X}$ & & & $\mathrm{X}$ & \\
\hline Agustín González & & & $\mathrm{X}$ & \multicolumn{2}{|c|}{ Dirigente Cooperativa } & $\mathrm{X}$ & \\
\hline Lorenzo Carpanchay & $\mathrm{X}$ & & & & & $\mathrm{X}$ & \\
\hline Juan Toroco & $\mathrm{X}$ & & & & & & $X$ \\
\hline Vidal Mondaca & $X$ & & & & & & $\mathrm{X}$ \\
\hline Rosendo Cruz Puca & $\mathrm{X}$ & & & & & & $\mathrm{X}$ \\
\hline Misael Mondaca & $\mathrm{X}$ & & & & & & $\mathrm{X}$ \\
\hline Miguel González & $\mathrm{X}$ & & & & & & $\mathrm{X}$ \\
\hline Nelson Mondaca & $X$ & & & & & & $\mathrm{X}$ \\
\hline Sebatian Tejerina & $\mathrm{X}$ & & & & & & $\mathrm{X}$ \\
\hline Pacífico Mondaca & $\mathrm{X}$ & & & & & & $\mathrm{X}$ \\
\hline Manuel Reyes & $\mathrm{X}$ & & & & & & $\mathrm{X}$ \\
\hline Angel Puca & & & $\mathrm{X}$ & & & & $\mathrm{X}$ \\
\hline Tito Mamani & $\mathrm{X}$ & & & & & & $\mathrm{X}$ \\
\hline Rolando Rodríguez & $\mathrm{X}$ & & & & & & $\mathrm{X}$ \\
\hline Galindo Liendro Reyes & $X$ & & & & & & \\
\hline Concepción Silvestre & $\mathrm{X}$ & & & & & & \\
\hline Josefina Plaza & $\mathrm{X}$ & & & & & $\mathrm{X}$ & \\
\hline Rosario Liquitay & & & $\mathrm{X}$ & & & $\mathrm{X}$ & \\
\hline Fortunata Liendro & & & $\mathrm{X}$ & & & $\mathrm{X}$ & \\
\hline Catalino Tejerina & $\mathrm{X}$ & & & & & $\mathrm{X}$ & \\
\hline Héctor González & $\mathrm{X}$ & & & & & & \\
\hline Aniceto Reyes & $\mathrm{X}$ & & & & & & \\
\hline
\end{tabular}

Cuadro 2. Artesanos de Toconao. 
Todos emparentados entre sí. ${ }^{5}$

Viven en gran medida en función de Toconao; venden allí sus productos artesanales: mantas, frazadas, llamitos, calcetas, lazos, tambores, clarines, figuritas en piedra volcánica, siendo de todos ellos la más importante la línea textil.

\section{Socaire}

Ubicación geográfica: $23^{\circ} 35^{\prime}$ Lat. $S ; 67^{\circ} 35^{\prime}$ Long. O.

Altura: 3250 m.snm.

Pueblo que vive de una ganadería y agricultura primitiva. A pesar de ello podría autoabastecerse y subsistir. Construyen sus casas con materiales del lugar y con sus propias técnicas tradicionales: piedra barro y techos de paja. Cuentan con piedra blanca (liparita), la cual se cantea con bastante prolijidad (influencia reciente de Toconao); pero no se producen artesanías con ella, siendo Socaire un pueblo de artesanos.

La principal producción artesanal son los tejidos. En primer lugar se autoabastecen de ropas y otros utensilios de lana y, en segundo lugar, venden.

La importancia de la actividad artesanal se puede apreciar en el hecho de que por la lana vendida en bruto obtienen una quinta parte de su valor con respecto al $\mathrm{kg}$ de lana elaborada. Este ingreso es indispensable para el pueblo. La ganadería y agricultura que tienen, no absorbe 8 horas diarias todos los días a todos y no hay otras fuentes de trabajo que la artesanía y la construcción. ${ }^{6}$ Los trabajos se realizan normalmente por temporadas y varios de ellos en forma comunitaria. Se organizan en juntas de Vecinos.

El tejido constituye una artesanía tradicional y con buena técnica. Las condiciones que se dan en Socaire son excepcionalmente buenas para intensificar las artesanías textiles.

5 Emiliano Cruz y Juan Cruz, jóvenes artesanos que han participado en el curso de alfombrería 1974.

615 hombres de este pueblo trabajan durante la temporada de verano en el mineral de hierro de El Laco.
Materia prima. Socaire cuenta con lana de llamo y de oveja. En total las majadas del pueblo suman aproximadamente 4180 lanares y 123 llamos. No todos los artesanos son propietarios de animales. Por lo general, quien menos animales tiene más necesita de la venta de sus tejidos. Algunos trabajan "en medias", poniendo uno la lana y el otro su trabajo.

Es preferible la lana de llamo, tanto por la variedad de los colores naturales como por la calidad de la fibra. Esta es, por supuesto, mucho más escasa y más cara que la de oveja, principalmente por producir cada animal menos lana, ya que ésta última da una esquila cada 2 o 3 años con un peso de vellón similar al que rinde la oveja en un año. El rindis es mayor por kilo, ya que es mucho más limpia y menos grasosa. La esquila se hace en noviembre. Se carda, se hila y después se lava. Todo esto se realiza a mano. También usan anilinas que se compran en el comercio de Calama o de Argentina. No se utilizan las tinturas naturales primitivas.

Herramientas. Se teje a palillo, en telar de suelo y en telar de campo. Estos últimos son fabricados por los mismos artesanos, en especial hombres.

Productos. Se tejen fajas, pisos, frazadas, mantas, telas para ropa (pantalones, chaquetas, etc.), llamitos, calcetas, gorros simples y esquemáticos en el diseño.

Venta. Está restringida a la Cooperativa de Toconao $\mathrm{y}$ al paso de turistas.

Necesidades. Normalmente una tejedora puede producir aproximadamente $100 \mathrm{k}$ de tejidos al año, alternando con el trabajo hogareño y la agricultura. Hay 79 artesanos, los que requerirían alrededor de $8000 \mathrm{k}$ de lana al año, pero parte de la producción de lana se vende en bruto a los artesanos de pueblos vecinos, lo que produce un agotamiento de la materia prima, varios meses antes de la siguiente temporada de esquila. La población lanar ha disminuido estos últimos años a causa de la sequía y de la compra por parte de los carniceros de Calama, a precios elevados de animales en pie y especialmente los nacidos en la temporada que dan sobre los $10 \mathrm{k}$ de carne para el mes de septiembre. Esto ha hecho vender de manera indiscriminada los machos y las hembras en base exclusivamente al peso. Esta medida es pésima y su efecto se hace sentir a los 2 
o 3 años con una merma de animales de vientre y por lo tanto de la producción en general. ${ }^{7}$ Las necesidades fundamentales son en primer lugar asegurar un buen abastecimiento de lana y en lo posible de la lana de llamo. En segundo lugar, fomentar una mayor variedad en el diseño textil y una vuelta a las tinturas primitivas y, tercero, asegurar una venta con pago inmediato, lo que evitaría la venta de lana en bruto y un mayor estímulo a producir.

Socaire ha experimentado un aumento considerable de la población entre 1971-1974. Quince hombres trabajan la temporada en el mineral de hierro El Laco. También ha experimentado un aumento la población lanar por sobre las 1000 cabezas.

Socaire tiene 400 habitantes: 228 mujeres, 182 hombres, 75 familias.

\section{Artesanos de Socaire:}

Tejidos:

Julia Mora

María Cruz

Isabel Cruz

Protasia Ramos

Isabel Cruz

Berta Cruz

Catalina Varas

Elvira Tejerina

Anita Varas

Nemesia Varas

Natalia Varas

Jovita Varas

Berta Cruz

Ceferina Plaza

Sonia Reales

María Luisa Carral

Modesta Plaza

Paulina Cruz de

Buston

Natalia Morales

Martina Carral

Ubeldina Plaza

Ventura Cruz

Felipa Cruz

Brígida Cruz
Hombres que hacen tejidos de lazos, riendas, etc.:

Joaquín Cruz

Manuel Cruz

Gilberto Cruz

Nicolás Bustos

Demetro Cruz

Teodoro Cruz

Reimundo Plaza

Santiago Plaza ${ }^{8}$

Domingo Plaza

Donisio Cruz

Martín Cruz

Rubén Cruz

Nelson Cruz

Juan Cruz Real

Celedonio Varas

Silverio Cruz

Pablo Cruz

Joaquín Plaza

Armando Plaza ${ }^{8}$

Santiago $\mathrm{Cruz}^{8}$

Juan Silvestre ${ }^{8}$

Saturnino Tejerina

Laureano Tejerina

Tomás Morales

Carlos Plaza

Silvestre Varas

Albino Plaza

Miguel Pachao

Crinolfo Cruz

Aldo Plaza ${ }^{8}$

\section{San Roque de Peine}

Ubicación geográfica: $23^{\circ} 43^{\prime}$ Lat. S; $68^{\circ} 06^{\prime}$ Long. O.

Altura: 2600 m.snm

Situado a $90 \mathrm{~km}$ al sur de San Pedro de Atacama. Vive de la agricultura y de su producción artesanal. Varios jefes de familia (aproximadamente 15) trabajan en la estación ferroviaria de Monturaqui, que queda a 2 días de trayecto a lomo de mula desde Peine. Es importante mencionar a este grupo de hombres, ya que desde Monturaqui traen no sólo sus sueldos, sino ónix verde. Tallan este material en sus horas libres en la estación. Este trabajo de lapidaria es reciente, por lo cual sus resultados son un tanto burdos y sus cultores no muy numerosos.

Alrededor de Peine se encuentra ónix veteado con el cual se hacen pequeños objetos decorativos.

Se hacen, además, tallados en madera de frutales, pero por la escasez de árboles esta artesanía sólo podría mantenerse como complemento de las otras. Si bien hay tejedoras, Peine cuenta con muy poco ganado, por lo que se hace necesario adquirir lana en San Pedro y en Socaire.

También hay personas que trabajan la madera del cactus seco.

Existe gran interés por parte de los artesanos y de la Junta de Vecinos por recibir cursos para mejorar sus 
artesanías en piedra creando un taller comunitario de lapidaria.

Han aparecido nuevos tipos de trabajos, especialmente aprovechando los cueros de los animales beneficiados.

Problemas:

1. Falta de lana.

2. Falta de mercado.

3. Falta de equipo y herramientas para lapidaria.

4. Superar problemas de energía eléctrica puesto que el generador está en su tope.

\section{Artesanos de Peine:}

Lino Cruz Plaza, trabaja en Monturaqui en el Ferrocarril a $90 \mathrm{~km}$, aproximadamente, de distancia. Talla ónix, ceniceros, figuras colgantes. La señora trabaja en tejidos.

En Monturaqui hay por lo menos cinco personas que trabajan el ónix.

David Chaile Morales, trabaja en Monturaqui. Talla el ónix y la piedra veteada. La esposa, Adelina Barrera Ramos, trabaja en tejidos.

Santiago Chaile, trabaja en Monturaqui. Talla el ónix.

Sabiniaria Morales viuda de Chaile, tiene telar y trabaja en tejidos.

Meletina Carral, trabaja en tejidos de frazadas, llamitos, calcetines, bolsos, pisos.

José Morales, trabajos en cactus, cucharas de palo, martillos de palo, platos de madera.

Germán Morales, martillos de palo y cucharas de palo.

Julia Torres, tejidos de frazadas, calcetines, llamos.

Arinolfo Morales, trabaja el ónix en Monturaqui.

María Illapura, trabaja en tejidos.

Ceferino Mora, trabaja el cactus y martillos de palo.

Paulino Cruz, Presidente Junta de Vecinos, albañil, carpintero, herrero.

Benita Plaza, tejidos.

Pedro Segundo Barreda, ónix y piedra veteada.

Teófila Morales, tejidos.

Lucila Ramos, tejidos. El esposo trabaja en Monturaqui.

Rufina Torres, tejidos.

Ignacio Torres, martillos, cucharas de palo, trenzas de lana.

Bonifacia Morales, tejidos.
Patricia Torres, tejidos.

Claudio Morales, cactus, carpintero.

Eleodora Cruz, tejidos.

Anselma Illapura, tejidos.

Vicente Consué, Secretario Junta de Vecinos, hace trenzas de lana.

Yolanda Chaile, tejidos, llamita, caballo.

Eugenia Pachao, tejidos de calcetines, fajas, guantes, teje a espina.

Guillermo Chaile, artesanías de madera de cactus y martillos y cucharas de palo.

Estefanía Morales, tejidos.

Inés Chaile, tejidos. El esposo trabaja en Baquedano en el F.C.A.B.

Juan Morales, gorrito, mortero.

Daniela Chaile, cocos.

Adelina Barrera, tejidos.

Delfín Chaile, trabaja madera de cactus y algarrobo.

Daisy Cruz, tejidos.

Horacio Morales, torre.

Nicolás Ramos, San Pedro.

\section{Conclusiones}

Es evidente la necesidad y vocación que han demostrado los habitantes de los pueblos mencionados con respecto a sus artesanías. A pesar de que en 10 años no se construye una tradición artesanal, se puede afirmar que se ha iniciado una con resultados inesperados. Tal es el caso de los tallados en piedra volcánica gris y liparita. En la línea de los tejidos, se ha diversificado el producto, aumentando además el volumen de éste, pero con una baja en la calidad del mismo.

Los trabajos en madera de cactus tienen el problema de que cada vez es más escasa la materia prima. Así también es limitado el tallado en madera de frutales.

Se aprecia una búsqueda de nuevos productos en otras materias (cuero y ónix).

La artesanía en piedra de Toconao debe virar en parte hacia un sentido más funcional. La novedad deja de ser tal en poco tiempo. La torrecita de Toconao ha invadido el país.

Aunque la producción artesanal es bastante semejante de un pueblo a otro, las posibilidades de desarrollo de ella están determinadas por sus recursos propios $\mathrm{y}$ es conveniente incentivarlas del siguiente modo: 
San Pedro de Atacama. Cerámica.

Toconao. Tallado en piedra volcánica gris y liparita, especialmente.

Camar. Textiles e instrumentos musicales.

Socaire. Textiles.

Talabre. Textiles.

Peine. Lapidaria y tallado en madera.

Las necesidades pueden resumirse en las dos siguientes:

1. Cauce de comercialización directo. Este último debe ir acompañado de una promoción del turismo hacia esta región.

2. Aporte en herramientas y talleres vecinales.

Los peligros que conlleva cualquier acción son:

a) Imposición de fórmulas, sean éstas de un purismo autóctono o diseños foráneos. b) Un fomento excesivo. Al igual que una planta, las artesanías han de crecer y desarrollarse por su propia vitalidad. El forzar su desarrollo es como querer hacer crecer una planta tirándole de sus hojas, con lo que sólo se logrará desenraizarla.

Agradecimientos. Este trabajo se ha realizado con la valiosa cooperación de Ronald Clunes L., prof. del Departamento de Artes Visuales de la Universidad del Norte y del alumno-ayudante Nelson Astudillo, quienes colaboraron en el levantamiento del catastro de artesanos en 1971. José P. Reyes Franzani, geógrafo del Departamento de Ciencias Sociales de la Universidad del Norte, quien facilitó material inédito sobre la zona. George Serracino, del Museo de San Pedro de Atacama, por sus observaciones y consejos. Y el reconocimiento a Bernardo Tolosa, Ingeborg Lindberg y Luis Araneda, quienes trabajaron en el Plan Cordillera entre 1963 y 1967. 